\title{
Digital Health Professions Education in the Field of Pediatrics: Systematic Review and Meta-Analysis by the Digital Health Education Collaboration
}

Serena Brusamento ${ }^{1}$, MPH, MD; Bhone Myint Kyaw ${ }^{2}$, MSc, MBBS, PhD; Penny Whiting ${ }^{3}$, BA, MSc, PhD; $\mathrm{Li} \mathrm{Li}^{4}$, MSc, MPH, MD; Lorainne Tudor Car ${ }^{1,5}$, MSc, MD, PhD

\footnotetext{
${ }_{1}^{1}$ Department of Primary Care and Public Health, School of Public Health, Imperial College London, London, United Kingdom

${ }^{2}$ Centre for Population Health Sciences, Lee Kong Chian School of Medicine, Nanyang Technological University, Singapore, Singapore

${ }^{3}$ Population Health Sciences, Bristol Medical School, University of Bristol, Bristol, United Kingdom

${ }^{4}$ Office of Medical Education, Lee Kong Chian School of Medicine, Nanyang Technological University, Singapore, Singapore

${ }^{5}$ Family Medicine and Primary Care, Lee Kong Chian School of Medicine, Nanyang Technological University, Singapore, Singapore
}

\section{Corresponding Author:}

Lorainne Tudor Car, MSc, MD, PhD

Family Medicine and Primary Care

Lee Kong Chian School of Medicine

Nanyang Technological University

11 Mandalay Road

Singapore

Singapore

Phone: 6569041258

Email: lorainne.tudor.car@ntu.edu.sg

\section{Abstract}

Background: Reducing childhood morbidity and mortality is challenging, particularly in countries with a shortage of qualified health care workers. Lack of trainers makes it difficult to provide the necessary continuing education in pediatrics for postregistration health professionals. Digital education, teaching and learning by means of digital technologies, has the potential to deliver medical education to a large audience while limiting the number of trainers needed.

Objective: The goal of the research was to evaluate whether digital education can replace traditional learning to improve postregistration health professionals' knowledge, skills, attitudes, and satisfaction and foster behavior change in the field of pediatrics.

Methods: We completed a systematic review of the literature by following the Cochrane methodology. We searched 7 major electronic databases for articles published from January 1990 to August 2017. No language restrictions were applied. We independently selected studies, extracted data, and assessed risk of bias, and pairs of authors compared information. We contacted authors of studies for additional information if necessary. All pooled analyses were based on random effects models. We included individually or cluster randomized controlled trials that compared digital education with traditional learning, no intervention, or other forms of digital education. We assessed the quality of evidence using the Grading of Recommendations, Assessment, Development, and Evaluations (GRADE) criteria.

Results: Twenty studies (1382 participants) were included. Participants included pediatricians, physicians, nurses, and midwives. Digital education technologies were assessed including high-fidelity mannequins (6 studies), computer-based education (12 studies), mobile learning (1 study), and virtual reality (1 study). Most studies reported that digital education was either as effective as or more effective than the control intervention for outcomes including skill, knowledge, attitude, and satisfaction. High-fidelity mannequins were associated with higher postintervention skill scores compared with low-fidelity mannequins (standardized mean difference $0.62 ; 95 \%$ CI 0.17-1.06; moderate effect size, low-quality evidence). One study reported physician change in practicing behavior and found similar effects between offline plus online digital education and no intervention. The only study that assessed impact on patient outcome found no difference between intervention and control groups. None of the included studies reported adverse or untoward effects or economic outcomes of the digital education interventions. The risk of bias was mainly unclear or high. The quality of evidence was low due to study inconsistencies, limitations, or imprecision across the studies. 
Conclusions: Digital education for postregistration health professions education in pediatrics is at least as effective as traditional learning and more effective than no learning. High-fidelity mannequins were found to be more effective at improving skills than traditional learning with low-fidelity mannequins. Computer-based offline/online digital education was better than no intervention for knowledge and skill outcomes and as good as traditional face-to-face learning. This review highlights evidence gaps calling for more methodologically rigorous randomized controlled trials on the topic.

Trial Registration: PROSPERO CRD42017057793; https://tinyurl.com/y5q9q5o6

(J Med Internet Res 2019;21(9):e14231) doi: 10.2196/14231

\section{KEYWORDS}

digital education; randomized controlled trials; pediatrics; systematic review; meta-analysis; traditional learning; high-fidelity mannequins

\section{Introduction}

Reducing childhood morbidity and mortality is a global health priority. Mortality remains high in many low- and middle-income countries (LMIC), despite improvements achieved as a result of the Millennium Development Goals [1,2]. Reducing childhood mortality and ensuring global access to health care through health workforce development is one of the 17 United Nations Sustainable Development Goals [3-5]. A major factor in reducing childhood morbidity and mortality is the quality of pediatric health care. This is influenced by the skills of the health professionals-physicians, nonphysician clinicians, nurses, and midwives. To provide optimal care, health professionals need continuous, high-quality, and up-to-date education [6]. Lack of access to learning resources, coupled with remote locations, limited health professionals, and a need for the ongoing provision of health services represent significant barriers to health professions education in many settings.

Pediatric health professions education is particularly important due to the unique nature of the diseases, need for timely and appropriate treatment, and the narrow margin of treatment error compared with the adult patients [7]. Additionally, there is a growing demand to educate pediatrics health professionals in certain topics that need timely incorporation/implementation of evidence-based recommendations and guidelines such as delivering updated guidelines on immunizations [8], chemotherapy [9], respiratory infections [10], and neonatal management [11]. Traditional forms of education such as face-to-face or didactic lectures or workshops might not be adequate to address these demands in a timely manner, and digital education can be an alternative option for educating pediatric health professionals as it provides an efficient, timely, and convenient mode for the learners which further helps to improve outcomes [12].

Digital education helps overcome resource, geographical, and time barriers. Computer-based and mobile learning allow learners to access educational materials without time or place restrictions, allowing them to work at their own pace and time from any location [13]. A further advantage of this type of learning is that it generally requires fewer tutors. Unlike face-to-face lectures or tutorials, the number of learners who can participate in this type of education is far greater. Computer-based offline digital education provides increased access to learning materials with limited internet connectivity $[14,15]$. Mobile learning or mLearning supports learning in a similar way by enhancing the delivery of learning materials without time and place limitation through a handheld mobile device. There are a number of mobile device-based functions such as short message service (SMS or texts), multimedia message service, podcasts, and mobile apps that support the delivery of educational materials based on the needs of learners and learning processes [16,17].

Simulation-based medical education such as training in virtual reality environments and virtual patient scenarios supports creation of 3D virtual world or patient case-based scenarios that are similar to real-life clinical scenarios, designed specifically for health professional training [18-20]. Similarly, training via psychomotor skills trainers such as high- or middle-fidelity mannequins allows for training of different types of psychomotor or technical skills acquisitions such as resuscitation and suturing skills [21-23].

The potential benefits of digital education for health professions education have been evaluated in previous reviews and acknowledged by the World Health Organization [12-14,24-27]. While there are reviews on the use of digital education in specific pediatric fields (eg, emergency or rehabilitation care) and for undergraduate education [28-30], we are unaware of any systematic review assessing the effectiveness of digital education in the field of pediatrics for postregistration health professionals. This review evaluates the effectiveness of different modalities of digital education for postregistration pediatrics health professionals in comparison with traditional learning or other forms of digital education. We assessed the impact of digital education on participants' knowledge, skills, attitudes, clinical practice, and satisfaction compared with other forms of learning.

\section{Methods}

\section{Systematic Review}

The protocol for the systematic review was registered with PROSPERO [CRD42017057793] [31]. For a detailed description of the methodology, please refer to the methods as described by the Digital Health Education Collaboration [32], a global initiative focused on evaluating the effectiveness of digital health professions education through a series of methodologically robust systematic reviews.

For the purpose of this review, digital education can be defined as "an approach to teaching and learning, representing all or 
part of the educational model applied, that is based on the use of electronic media and devices as tools for improving access to training, communication and interaction, that facilitates the adaptation of new ways of understanding and developing learning" [33]. Digital education encompasses a variety of learning modalities including computer-based online/offline digital education (online/offline digital education), high-fidelity mannequins, virtual reality environments, virtual patient scenarios, serious gaming and gamification, and mobile learning, etc $[15,20,27,34-36]$. It is often combined with traditional nondigital learning, known as blended learning. Traditional learning means learning via traditional forms of education such as paper- or textbook-based learning, didactic or face-to-face lectures, tutorials, box trainers, or low-fidelity mannequins.

\section{Inclusion Criteria}

We included studies involving learners who were enrolled in any postregistration health professional or continuing medical education (CME) programs. For this review, postregistration health professional programs can be defined as any type of study after a qualification which is recognized by the relevant governmental or professional bodies that enables the qualification holder entry into or continuation of work in the health care workforce in a more independent or senior role. We also included studies focusing on CME programs that involved the use of digital education to deliver the learning contents. We included all postregistration health professionals listed in the Health Field of Education and Training (091) of the International Standard Classification of Education except professionals from traditional, alternative, and complementary medicine [31].

We included individually or cluster randomized controlled trials (RCTs) that compared digital education interventions on any pediatric-related topic for postregistration health professions with traditional learning, no intervention, or other forms of digital education [37]. Eligible studies had to report at least one of the specified primary or secondary outcomes. Primary outcomes (measured using any validated or nonvalidated instruments) were (1) participants' knowledge scores, (2) participants' skills, and (3) participants' attitudes toward the interventions or toward new clinical knowledge. Secondary outcomes included participants' satisfaction with the intervention, participants' change in clinical practice, the economic impact of digital education (eg, cost and cost effectiveness), patient-related outcomes, and any adverse or unintended effects of digital education.

\section{Search Strategy and Data Sources}

We developed a comprehensive search strategy for 7 electronic databases: MEDLINE (Ovid), Embase (Elsevier), Cochrane Central Register of Controlled Trials (Wiley), PsycINFO (Ovid), Educational Research Information Center (Ovid), Cumulative Index to Nursing and Allied Health Literature (Ebsco), and Web of Science Core Collection (Thomson Reuters). The databases were searched for articles published from January 1990 to August 2017 without language or publication restrictions; studies published prior to this were not considered due to technological advances (Multimedia Appendix 1). We searched reference lists of all the studies that we deemed eligible for inclusion in our review and relevant systematic reviews. We also searched the
International Clinical Trials Registry Platform Search Portal and metaRegister of Controlled Trials to identify unpublished trials.

\section{Data Collection and Analysis}

The search results from different electronic databases were combined in a single Endnote library, and duplicate records were removed. Three review authors (SB, BMK, and LL) independently screened titles and abstracts of all the records to identify potentially eligible studies. We retrieved full-text copies of the articles deemed potentially relevant. Finally, three reviewers (SB, BMK, and LL) independently assessed the full-text versions of the retrieved articles against the eligibility criteria. Any disagreements were resolved through discussion between the reviewers.

\section{Data Extraction and Management}

Each manuscript was independently extracted by two reviewers from a team of three (SB, BMK and LL). We extracted relevant characteristics related to types of participants (ie, doctors, nurses, or midwives), interventions used, comparators or control groups, outcome measures including details of assessment methods, and results from all included studies using a standard data collection form built on an Excel (Microsoft Corp) template (Multimedia Appendix 2). Any disagreements between the reviewers were resolved by discussion. We contacted study authors for any missing information, particularly information required to judge the risk of bias.

\section{Measures of Treatment Effect}

For continuous outcomes, we extracted mean postintervention scores, standard deviations (SD), and number of participants for each intervention group and control groups. We used these data to calculate standardized mean differences (SMD) with associated $95 \%$ confidence intervals using random effect models. For studies that reported only median and ranges, we converted these to mean and SD [38]. Dichotomous data were extracted as number of events and number of participants in each intervention group. These data were used to calculated odds ratios (ORs) with associated $95 \%$ confidence intervals using random effect models. We were unable to identify a clinically meaningful interpretation of effect size in the literature for digital education interventions. Therefore, in line with other studies in the field, we presented outcomes using postintervention SMD and interpreted the effect size using the Cohen rule $[39,40]$.

\section{Assessment of Risk of Bias in Included Studies}

Three reviewers (SB, BMK, and LL) independently assessed the methodological risk of bias of included studies in line with the Cochrane methodology [40]. This includes domains covering random sequence generation, allocation concealment, blinding (outcome assessment), completeness of outcome data (attrition bias), selective outcome reporting (relevant outcomes reported) and other sources of bias such as baseline imbalances, inappropriate administration of an intervention, and contamination.

For cluster RCTs (cRCTs), we also assessed the risk of the following additional domains: recruitment bias, baseline 
imbalance, loss of clusters, incorrect analysis, and comparability with individual RCTs as recommended by Puffer et al [41]. Judgments concerning the risk of bias for each study were scored as high, low, or unclear. Disagreements were resolved by consensus between the two authors or through discussion with a third author (Multimedia Appendix 3) [41].

\section{Data Synthesis}

We grouped studies by type of digital education, comparator group, and outcome. Where sufficient data were available, we used random effect meta-analysis to estimate summary effect estimates. Heterogeneity was assessed visually using forest plots and statistically using the $I^{2}$ statistic [42]. Where meta-analysis was not possible (except for skill outcome), a narrative synthesis was presented. We aimed to carry out prespecified subgroup analysis including the analysis based on country income such as LMIC versus HIC (high-income countries). However, due to the limited primary data, we were unable to conduct prespecified subgroup analyses.

We also prepared summary of findings tables for the major comparisons focusing on high-fidelity mannequins and computer-based education and assessed the overall quality of evidence by using GRADEprofiler (GRADEproGDT Web-based version, McMaster University) [43]. We presented the findings of the review based on Preferred Reporting Items for Systematic Reviews and Meta-Analyses statements, and details of the statements are presented in Multimedia Appendix 4. Descriptions of the terminologies used in this review are presented in Multimedia Appendix 5.

\section{Results}

\section{Search Results}

We used a common search strategy for a series of systematic reviews evaluating the effectiveness of digital education on different areas of health professions education. The overall searches identified 30,532 references. After reading titles and abstracts, 3466 references with different digital education interventions focusing on different areas of health professions education were identified, of which 54 studies focusing on pediatric education were selected for full-text review, and 20 trials fulfilled our inclusion criteria (1382 participants): 18 RCTs and two cRCTs (Figure 1). 
Figure 1. Flow of studies through the review process.

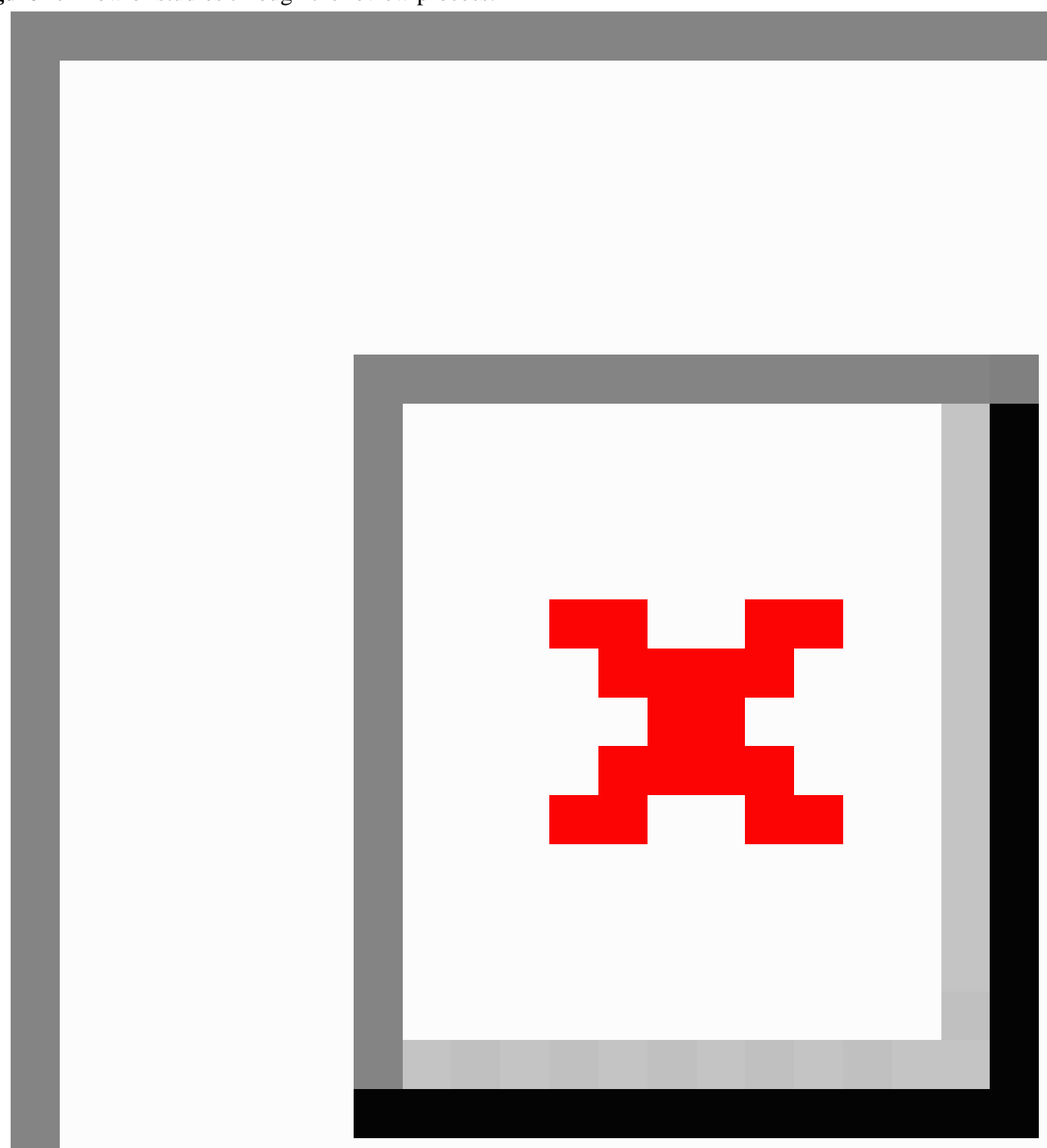

Three studies were performed in the LMICs India [44], Ethiopia [45], and Lebanon [23]. The remaining were performed in HICs: North America (13 studies), Europe (3 studies), and Asia (1 study). Digital education was used for education in a variety of pediatric fields (Multimedia Appendix 6): neonatal/pediatric resuscitation and intubation (8 studies) [21-23,44-48], childhood obesity ( 2 studies) [49,50], pediatric emergency (1 study) [51], firearm injury prevention (1 study) [52], detection of childhood abuse (1 study) [53], drug prescriptions (1 study) [54], pediatric sedation (1 study) [55], child emergency nursing care (1 study) [56], counseling for parent's smoking cessation (1 study) [57], pediatric orthopedic surgery (1 study) [58], and asthma (1 study) [59].

Participants in included studies were pediatricians ( 9 studies) [23,46,48,50-52,55,59,60]; postregistration nurses (4 studies) [22,44,53,56]; midwives and health extension workers ( 1 study) [45]; childcare health consultants (1 study) [49]; orthopedic surgery residents (1 study) [58]; family medicine residents (1 study) [47]; junior doctors (1 study) [54]; mixed participants including doctors, nurses, emergency technicians, and paramedics (1 study) [21]; and pediatric respiratory therapists and nurses (1 study) [57].

Seventeen studies were 2-arm studies: 9 compared digital education with traditional learning [21-23,44,45,47,48,56,58], 7 compared digital education with no intervention [50-54,57,59], and one compared 2 digital education methods [55]. Three studies included 3 intervention arms: 2 compared digital 
education with traditional learning and blended learning [46,60], and one compared digital education with traditional learning and no intervention [49]. Digital education technologies evaluated included high-fidelity mannequins (6 studies), computer-based education (12 studies), mLearning (1 study), and a virtual reality environment (1 study).

\section{Risk of Bias Assessment and Quality of Evidence}

The main limitation with the included studies was incomplete outcome data -5 studies were judged as high risk of bias for this domain $[45,50,55,59,60]$, and for 3 studies, there was insufficient information on missing data to make a judgement $[22,48,51]$. Many studies were poorly reported, making it difficult to judge risk of bias. Randomization, concealment of allocation, and blinding of outcome assessors were poorly reported, with 8,13 , and 12 studies, respectively, judged at unclear risk of bias for these domains. However, only single studies were judged as high risk of bias for randomization [22], blinding of outcome assessment domains [23], selective reporting [57], and other bias [44]. Additional domains assessed for the 2-cluster trials were all at low risk of bias (Figure 2). The quality of evidence was low due to study inconsistencies, limitations, and/or imprecision across the studies (Multimedia Appendix 7).

The detailed results of included studies are presented in Multimedia Appendix 8. Where available, standardized mean differences are presented in Figures 3-5.

\section{High-Fidelity Mannequins}

Six studies (320 participants) assessed the use of high-fidelity mannequins to provide training in neonatal or pediatric resuscitation, 5 compared with low-fidelity mannequins $[21,23,47,48,60]$ and one compared with traditional learning with checklist procedure training [56]. One study included an additional intervention group consisting of blended learning where participants receiving training used high-fidelity mannequins combined with team training [60].

All studies assessed participants' psychomotor skill scores, although different measures of skill were used including time to complete different steps of the intubation and resuscitation, number of redirections provided during the procedure, and performance checklists for different tasks. Overall, high-fidelity mannequins were associated with greater postintervention skill scores compared with low-fidelity mannequins (SMD 0.62; $95 \%$ CI 0.17 to $1.06 ; I^{2}=53 \%, 5$ studies; Figure 3 ). One study compared high-fidelity mannequins with traditional learning with checklist procedure training and reported higher postintervention skill scores in the intervention group (SMD 0.86 ; $95 \%$ CI 0.27 to 1.44 ; Figure 4) [56]. The study that included an additional blended learning group reported greater improvement in skill in the blended learning group compared with low-fidelity mannequins alone (SMD 1.34; 95\% CI 0.82 to 1.87 ) [60]. 
Figure 2. Risk of bias summary: review authors' judgements about each risk of bias item across all included studies.

\begin{tabular}{|c|c|c|c|c|c|c|c|}
\hline & 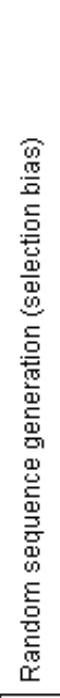 & 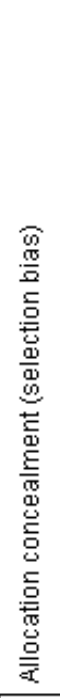 & 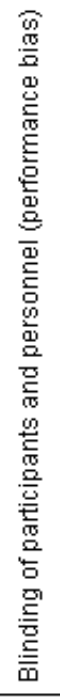 & 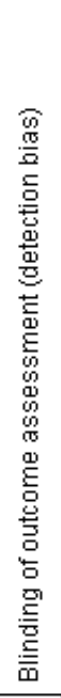 & 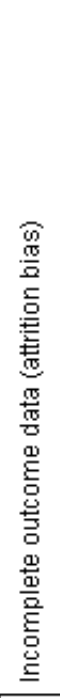 & 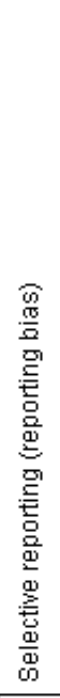 & 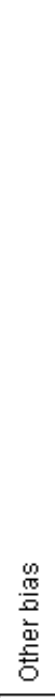 \\
\hline Alade 2012 [51] & $?$ & $?$ & + & $?$ & $?$ & $?$ & $?$ \\
\hline Benjamin 2008 [49] & + & + & + & $?$ & + & + & + \\
\hline Campbell 2009 [47] & + & $?$ & + & + & + & + & $\odot$ \\
\hline Dingeldein 2012 [52] & $?$ & $?$ & + & $?$ & + & + & $\odot$ \\
\hline Donoghue 2007 [48] & + & $?$ & + & $?$ & $?$ & $\oplus$ & $\odot$ \\
\hline Gordon 2011 [54] & + & + & + & + & 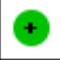 & 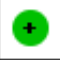 & + \\
\hline Gordon 2013 [57] & + & + & + & $?$ & + & - & + \\
\hline Hearty 2013 [58] & + & + & + & $?$ & + & + & + \\
\hline Jain 2010 [44] & + & + & + & + & + & + & \\
\hline Kim 2016 [56] & $?$ & $?$ & 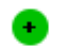 & $?$ & + & + & + \\
\hline Koele-Schmidt 2016 [46] & + & + & + & $?$ & 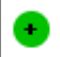 & 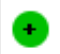 & $\odot$ \\
\hline Le 2010 [59] & $?$ & $?$ & 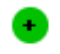 & $?$ & $\odot$ & + & + \\
\hline Lund 2016 [45] & + & 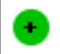 & $\oplus$ & $?$ & - & + & + \\
\hline Pollak 2016 [50] & $?$ & $?$ & + & + & - & + & \\
\hline Sharara-Chami 2014 [23] & $?$ & $?$ & + & 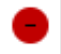 & + & + & + \\
\hline Smeekens 2011 [53] & + & $?$ & + & + & + & $?$ & + \\
\hline Stellflug 2016 [21] & $?$ & $?$ & 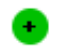 & $?$ & + & + & $\odot$ \\
\hline Thomas 2010 [60] & + & $?$ & + & $?$ & & $?$ & \\
\hline Vestergaard 2011 [22] & $\odot$ & $?$ & + & + & $?$ & + & $\odot$ \\
\hline Zaveri 2016 [55] & $?$ & $?$ & 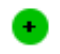 & 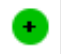 & - & + & + \\
\hline
\end{tabular}


Figure 3. Difference in postintervention skill between interventions using high-fidelity mannequins and low-fidelity mannequins.

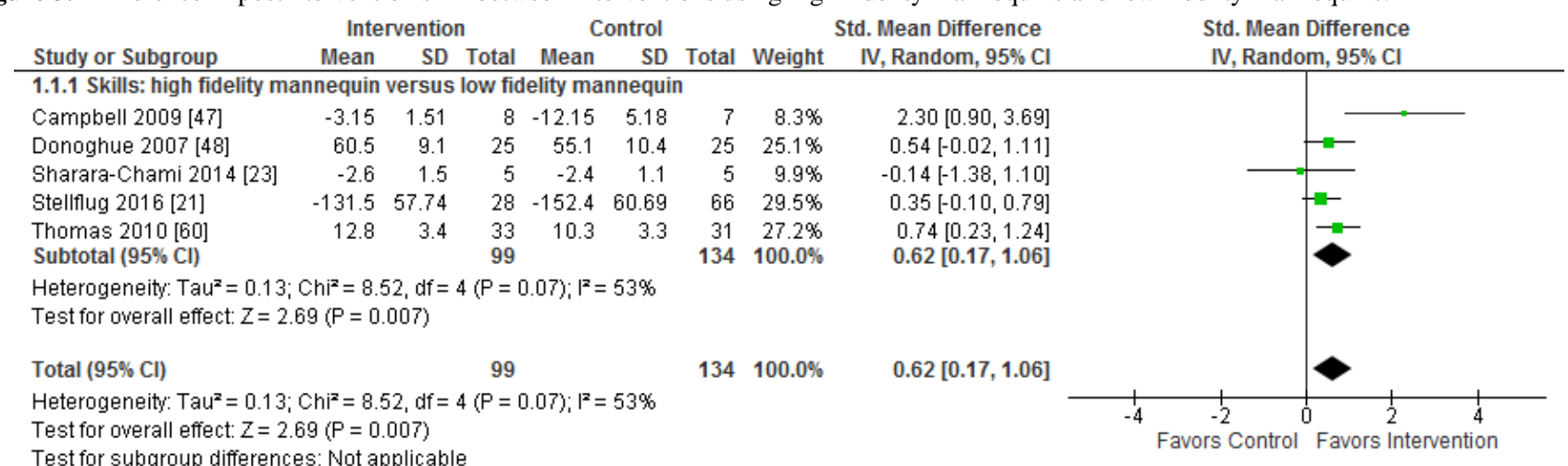

Figure 4. Difference in knowledge, skill, and satisfaction between interventions using high-fidelity mannequins and control groups.

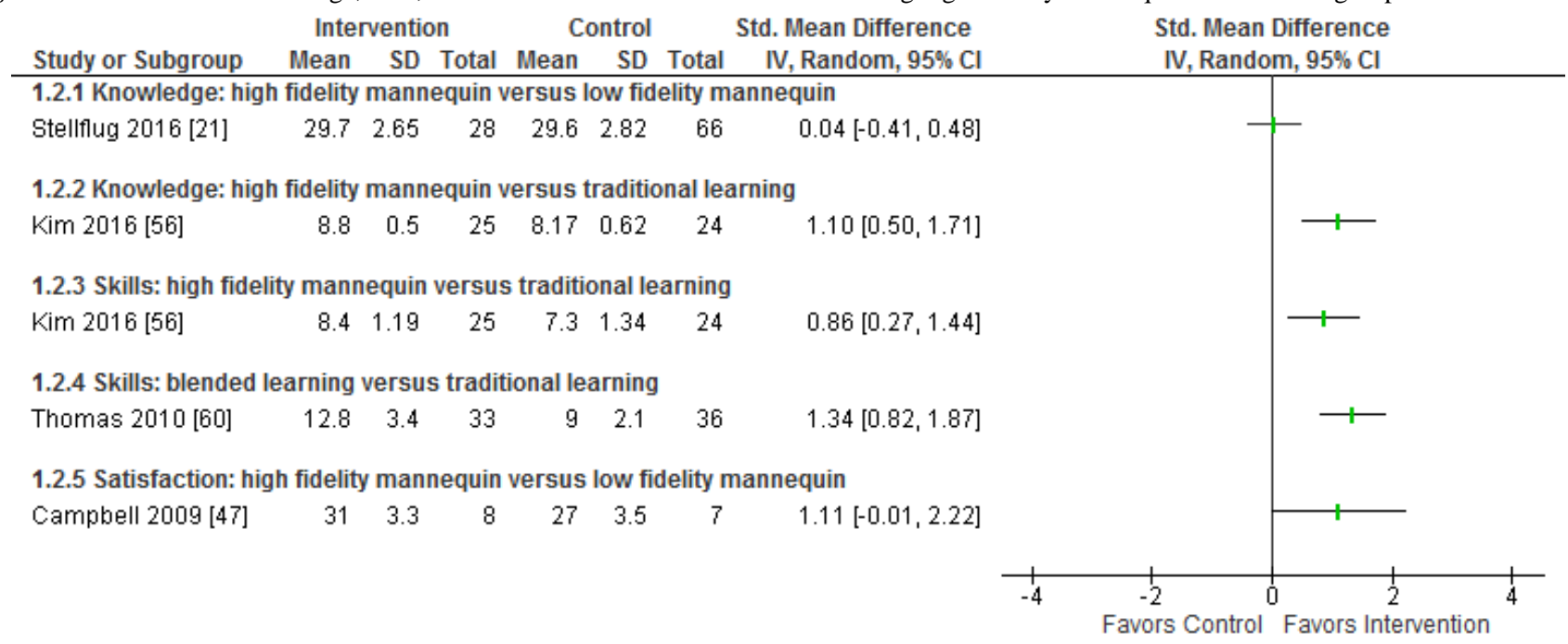

Two studies assessed knowledge [21,56]. One found that knowledge gain was greater with high-fidelity mannequins than with traditional learning (SMD 1.10; 95\% CI 0.50 to 1.71 ). The other found no difference between groups (SMD 0.04; 95\% CI -0.41 to 0.48 ). One study assessed participant satisfaction and found weak evidence for greater satisfaction with high-fidelity mannequins compared with low-fidelity mannequins (SMD $1.11 ; 95 \%$ CI -0.01 to 2.22 ).

\section{Computer-Based Education}

Twelve studies (854 participants) assessed computer-based education, 7 compared with no intervention, 3 compared with traditional learning, one compared with traditional learning and no intervention, and one compared with blended learning and traditional learning. Nine studies evaluated computer-based online education including Web-based modules, tele-education, PowerPoint presentations, and online modules with audio-recorded patient cases. Two studies assessed offline computer-based education using PowerPoint presentations and computer-based video teaching. One assessed both online and offline digital education (Web- or CD-ROM-based learning plus 2 conference calls).

Seven studies (442 participants) assessed participant psychomotor skills postintervention [22,44,46,50,51,53,54].
The studies used different types of outcome measures such as time to complete different steps of the intubation and resuscitation, number of redirections provided during the procedure, and performance checklist for different tasks. Three studies compared computer-based education (online, tele-education, online video learning, and offline computer module with pictures and videos) with traditional learning $[22,44,46]$; one study included an additional blended learning group [46]. None of the comparisons suggested a difference in postintervention skill between learning groups (Figure 5). Two studies [53,54] compared computer-based learning (PowerPoint presentation, software, flash program, videos, animations, and online webpage) with no intervention, all reported greater improvement in skill following computer-based learning (Figure 5). Two studies did not report data in an appropriate form to include on the forest plot. One compared digital education (bimonthly, brief Web-based computer modules) with traditional learning to improve ultrasonography skills for pediatric emergencies and reported higher scores in the online learning group compared with traditional learning $(P=.02)$ [51]. One study assessed primary care physicians' adolescent weight management skills and favored digital education (online learning containing patients' audio clips) over traditional learning $(P=.001)[50]$. 
Figure 5. Difference in knowledge, skill, attitude, and satisfaction between interventions using computer-based education and control groups.

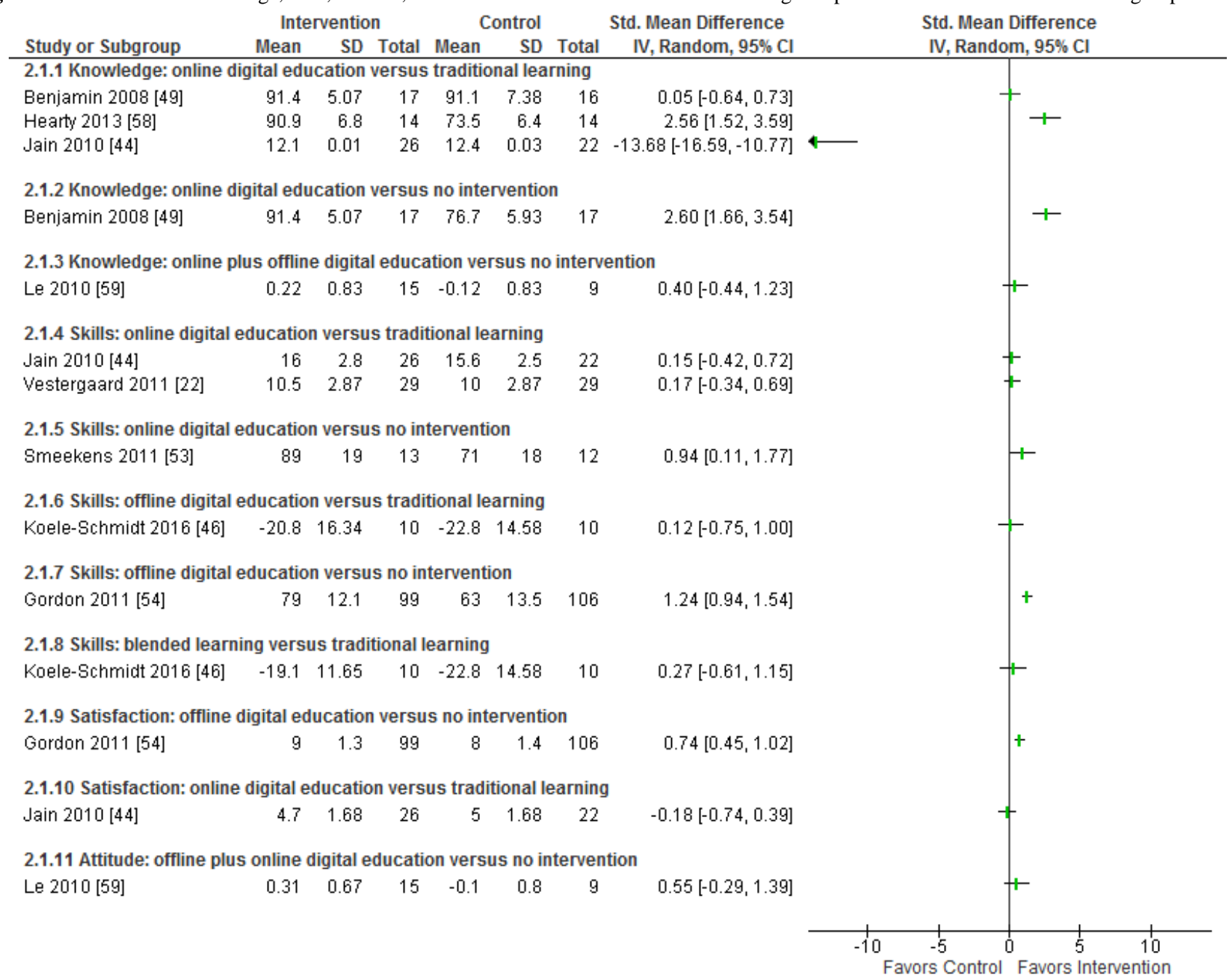

Five studies (244 participants) assessed the effect of computer-based learning on knowledge [44,49,52,58,59]. One 3 -arm study compared online education that included Web-based training on childhood weight management with traditional learning and no intervention. This study found no difference between online digital education and traditional learning (SMD $0.05 ; 95 \% \mathrm{CI}-0.64$ to 0.73 ) but reported greater knowledge scores following online digital education compared with no intervention (SMD 2.60; 95\% CI 1.66 to 3.54) [49]. A further study that compared online and offline digital education with no intervention did not find any difference in knowledge between groups (SMD 0.40; 95\% CI -0.44 to 1.23) [59]. Two studies compared online learning with traditional learning [44,58]. One found greater knowledge scores with online learning (SMD 2.56; 95\% CI 1.52 to 3.59) [58] and the other found better outcome in the control group at postintervention with adjusted pretest values (SMD -13.68; 95\% CI -16.59 to $-10.77)$. However, it showed no difference between groups with unadjusted pretest values (SMD $0.17 ; 95 \% \mathrm{CI}-0.40$ to 0.74 ) [44]. One study that compared online learning with no intervention only reported knowledge outcomes for the intervention group [52].

Three studies (333 participants) provided information on attitude $[52,57,59]$. One study provided sufficient data to calculate
SMDs; this study found no difference in attitude toward the intervention between digital education and no intervention groups (SMD 0.55; 95\% CI -0.29 to 1.39 ) [59]. Two studies only reported information on attitude toward the intervention in the online learning group, with both suggesting positive attitudes toward online digital education [52,57].

Six studies (615 participants) provided information on satisfaction, although only 2 reported data in a suitable format to allow inclusion in the forest plot (Figure 5). One study reported greater satisfaction with offline digital education compared with no intervention (SMD 0.74; 95\% CI 0.45 to 1.02) [54], and one study reported that participant satisfaction was similar for online digital education and traditional learning (SMD $-0.18 ; 95 \%$ CI -0.74 to 0.39 ) [44]. Four studies only reported data for the intervention groups and reported that participants were satisfied with online and offline digital learning in terms of duration of the intervention, usability, format, and design [52,57-59].

\section{Mobile Learning}

One study (176 participants) compared mLearning using a smartphone-based mobile app software with traditional learning to provide training in neonatal resuscitation to midwives and health extension workers. The study reported greater knowledge (SMD $0.91 ; 95 \%$ CI 0.60 to 1.22 ) and skill (SMD 0.99; $95 \%$ 
CI 0.68 to 1.30) scores in the mLearning group [45]. The study also assessed the impact on patient outcomes and found no difference in perinatal mortality rate between learning groups (OR $0.60 ; 95 \%$ CI 0.35 to 1.03 ).

\section{Virtual Reality Environments}

One small study (32 participants) compared a virtual reality environment (ie, commercial virtual learning platform, SecondLife, which provides computer-generated virtual patient scenarios for clinical cases management) with online digital education to provide training in pediatric sedation to pediatric residents. This study found no difference in skill (SMD 0.24; $95 \% \mathrm{CI}-0.47$ to 0.94$)$ [55] or knowledge $(P=.14)$ between groups. None of the included studies reported adverse or unintended effects of digital education interventions or economic outcomes.

\section{Discussion}

\section{Principal Findings}

We identified 20 studies assessing the effects of digital interventions for education in the field of pediatrics for postregistration health professionals. Included studies assessed a broad range of interventions, comparisons, and outcomes. All studies reported that digital education was either as effective as or more effective than the control intervention for outcomes including skill, knowledge, attitude, and satisfaction. Only one study with high risk of other bias due to baseline imbalances suggested that outcomes were worse with digital education compared with standard learning. All studies reported data on either skill or knowledge. One study reported physicians' change in practicing behavior and found similar effects between offline plus online digital education and no intervention. The only study to assess impact on patient outcome found no difference between intervention and control groups. The risk of bias was mainly unclear or high and the quality of evidence was low due to study inconsistencies, limitations, and/or imprecision across the included studies.

Studies assessed the use of different forms of digital education technologies such as high-fidelity mannequins (30\%), computer-based education (60\%), mLearning (5\%), and virtual reality environment $(5 \%)$. The majority of participants included in the studies were pediatric residents and junior doctors. Only four studies focused on nurses and one on midwives.

\section{Strengths and Limitations}

Our systematic review has a number of strengths. We followed Cochrane guidance to minimize the risk of bias in the review process [40]. We used the Grading of Recommendations, Assessment, Development, and Evaluations (GRADE) criteria and assessed the quality of evidence for each primary and secondary outcome for the comparison with high-fidelity mannequin and low-fidelity mannequin. We conducted a comprehensive search across a broad range of databases to identify relevant studies. We searched for studies going back to 1990 as we considered that studies published before this were unlikely to be applicable to current practice due to technological advances. We included any postregistration health professionals working in the field of pediatrics to cover all available evidence on different types of participants on the topic. We also covered studies of any type of digital education interventions, which are primarily designed to deliver learning contents for pediatric education to synthesize the most robust evidence on the use of digital education for pediatric education. We believe that covering different types of health professions using different digital education technologies for pediatric education would provide the most comprehensive evidence on the topic. We conducted a formal risk of bias assessment to identify potential sources of bias in the primary studies. Two independent reviewers were involved in all stages of the review process to minimize the risk of bias and errors.

The small number of included studies meant that it was not possible to carry out any subgroup analyses or assess the risk of publication bias. Therefore, there is likelihood of publication bias, and the chances of publication bias cannot be ruled out in this case. The only comparison for which sufficient data were available to estimate summary effect sizes was for the impact of high-fidelity mannequins compared with low-fidelity mannequins on skill. Differences in interventions evaluated, populations targeted, and outcomes assessed also precluded meta-analysis for other outcomes and types of digital education.

The main methodological limitation of the included studies identified by our risk of bias assessment was the large number of withdrawals in 5 of the included studies. Almost half of the studies ( 9 out of 20) did not report on methods of randomization or allocation concealment and so it was not possible to judge whether appropriate steps were taken to minimize the risk of bias for these domains. Details of the intervention were often poorly reported, and most studies used a nonvalidated instrument to assess outcomes. Some studies did not assess skill level before the intervention so an imbalance across groups cannot be excluded. None of the studies reported following the Consolidated Standards on Reporting Trials (CONSORT) statement [61] or any other reporting guidelines. Twelve out of 20 studies included fewer than 50 participants, which meant they were unlikely to have sufficient power to identify differences between intervention groups. Only 3 of the 20 included studies were conducted in LMICs, thus the results of our review may have limited applicability for policymakers in in these countries. There was limited information on outcomes such as attitude, satisfaction, patient outcomes, costs, and adverse or untoward effects of digital education.

We are not aware of any other systematic reviews that focus on the effectiveness of digital education interventions for health professions in the field of pediatrics. Our review highlights the most up-to-date and comprehensive evidence regarding the effectiveness of digital education on the topic.

Further primary studies are needed to assess the impact of digital education for continuation of education for health professionals in the field of pediatrics. Studies should compare digital education with traditional face-to-face learning rather than with no intervention. Possibilities to continue education of health care workers in LMICs are limited, and it is known that the level of knowledge and skills is lower than the level of postgraduate health care workers in HICs $[62,63]$. Therefore, it could be argued that digital education interventions could be 
advantageous in these settings. However, only 3 out of the 20 studies were conducted in these settings. With limited studies from LMIC and poor quality of evidence for reported outcomes, this means that the applicability of the evidence from our review might be limited for policymakers implementing health policies in these countries. Moreover, there is limited information on other outcomes such as attitude, satisfaction, costs, and adverse or untoward effect of digital education interventions.

\section{Conclusion}

Digital education for postregistration health professionals in pediatrics is at least as effective as traditional learning and more effective than no learning. High-fidelity mannequins were found to be more effective at improving psychomotor skills than traditional learning with low-fidelity mannequins. Computer-based offline/online digital education was better than no intervention for knowledge and skill outcomes and as good as traditional face-to-face learning. The evidence on other outcomes and other digital education modalities was limited. This review highlights evidence gaps in the field of digital education for health professions calling for more methodologically rigorous RCTs on the effectiveness of other forms of digital education such as mLearning, virtual reality environments, virtual patient scenarios, serious gaming and gamification, and massive open online courses for education of pediatric health professionals.

\section{Acknowledgments}

We gratefully acknowledge funding support from Nanyang Technological University Singapore (eLearning for Health Professional Education grant).

\section{Authors' Contributions}

SB and BMK had full access to all the data in the study and take responsibility for the integrity of the data and the accuracy of the data analysis. All authors were involved in study concept and design and acquisition, analysis, or interpretation of the data. SB, BMK, PW, LL, and LTC were involved in drafting the manuscript; all authors were involved in revision. LTC supervised the study.

\section{Conflicts of Interest}

None declared.

\section{Multimedia Appendix 1}

MEDLINE (Ovid) search strategy.

[PDF File (Adobe PDF File)31 KB-Multimedia Appendix 1]

\section{Multimedia Appendix 2}

Data extraction form.

[PDF File (Adobe PDF File)62 KB-Multimedia Appendix 2]

\section{Multimedia Appendix 3}

Risk of bias assessment for cluster randomized controlled trials.

[PDF File (Adobe PDF File)19 KB-Multimedia Appendix 3]

\section{Multimedia Appendix 4}

Preferred Reporting Items for Systematic Reviews and Meta-Analyses checklist.

[PDF File (Adobe PDF File)67 KB-Multimedia Appendix 4]

\section{Multimedia Appendix 5}

Glossary.

[PDF File (Adobe PDF File)33 KB-Multimedia Appendix 5]

\section{Multimedia Appendix 6}

Characteristics of studies.

[PDF File (Adobe PDF File)56 KB-Multimedia Appendix 6] 


\section{Multimedia Appendix 7}

Summary of findings table: effects of high fidelity mannequin on knowledge, skills, attitude, satisfaction, and behavior change outcomes.

[PDF File (Adobe PDF File)41 KB-Multimedia Appendix 7]

\section{Multimedia Appendix 8}

Results of the included studies.

[PDF File (Adobe PDF File)42 KB-Multimedia Appendix 8]

\section{References}

1. World Health Organization. World Health Statistics 2015 URL: http://apps.who.int/iris/bitstream/10665/170250/1/ 9789240694439 eng.pdf?ua=1\&ua=1 [accessed 2019-09-04]

2. World Health Organization. 2015. Progress Report on the Health-Related Millennium Development Goals URL: https:/ /www.who.int/en/news-room/fact-sheets/detail/millennium-development-goals-(mdgs) [accessed 2019-09-04] [WebCite Cache ID 77CjoJf1L]

3. Lassi ZS, Mallick D, Das JK, Mal L, Salam RA, Bhutta ZA. Essential interventions for child health. Reprod Health 2014;11 Suppl 1:S4 [FREE Full text] [doi: 10.1186/1742-4755-11-S1-S4] [Medline: 25177974]

4. Bale Jr SB, Lucas AO, editors. Reducing neonatal mortality and morbidity. In: Improving Birth Outcomes: Meeting the Challenge in the Developing World. Washington: Institute of Medicine (US) Committee on Improving Birth Outcomes; 2003:90-133.

5. United Nations (UN) General Assembly. 2015. Draft outcome document of the United Nations summit for the adoption of the post-2015 development agenda URL: https://digitallibrary.un.org/record/800852 [accessed 2019-09-04]

6. World Health Organization. 2015. Progress Report on Health Workforce Education, 2013-2015 URL: https://www.who.int/ hrh/documents/education training report13-15.pdf?ua=1 [accessed 2019-09-04] [WebCite Cache ID 77CjtzVAO]

7. Goldman R, Koren G. Keeping it safe in the paediatric emergency department - drug errors and ways to prevent them. Paediatr Child Health 2007 Jul;12(6):461-464 [FREE Full text] [Medline: 19030408]

8. Committee on Infectious Diseases. Recommended childhood and adolescent immunization schedules: United States, 2019. Pediatrics 2019 Mar;143(3):e20190065. [doi: 10.1542/peds.2019-0065] [Medline: $\underline{\text { 30824606] }}$

9. Unguru Y, Bernhardt MB, Berg SL, Johnson LM, Pyke-Grimm K, Woodman C, et al. Chemotherapy and supportive care agents as essential medicines for children with cancer. JAMA Pediatr 2019 May 01;173(5):477-484. [doi: 10.1001/jamapediatrics.2019.0070] [Medline: 30830204]

10. Miyakawa R, Barreto NB, Kato RM, Neely MN, Russell CJ. Early use of anti-influenza medications in hospitalized children with tracheostomy. Pediatrics 2019 Mar;143(3):e20182608. [doi: 10.1542/peds.2018-2608] [Medline: $\underline{30814271]}$

11. Vento M, Saugstad OD. Oxygen supplementation in the delivery room: updated information. J Pediatr 2011 Feb; $158(2$ Suppl):e5-e7. [doi: 10.1016/j.jpeds.2010.11.004] [Medline: 21238706]

12. Xu X, Posadzki PP, Lee GE, Car J, Smith HE. Digital education for health professions in the field of dermatology: a systematic review by Digital Health Education Collaboration. Acta Derm Venereol 2019 Feb 01;99(2):133-138 [FREE Full text] [doi: 10.2340/00015555-3068] [Medline: 30320871]

13. George PP, Papachristou N, Belisario JM, Wang W, Wark PA, Cotic Z, et al. Online eLearning for undergraduates in health professions: a systematic review of the impact on knowledge, skills, attitudes and satisfaction. J Glob Health 2014 Jun;4(1):010406 [FREE Full text] [doi: 10.7189/jogh.04.010406] [Medline: 24976965]

14. Rasmussen K, Belisario JM, Wark PA, Molina JA, Loong SL, Cotic Z, et al. Offline eLearning for undergraduates in health professions: a systematic review of the impact on knowledge, skills, attitudes and satisfaction. J Glob Health 2014 Jun;4(1):010405 [FREE Full text] [doi: 10.7189/jogh.04.010405] [Medline: 24976964]

15. Kyaw BM, Posadzki P, Dunleavy G, Semwal M, Divakar U, Hervatis V, et al. Offline digital education for medical students: systematic review and meta-analysis by the Digital Health Education Collaboration. J Med Internet Res 2019 Mar 25;21(3):e13165 [FREE Full text] [doi: 10.2196/13165] [Medline: 30907731]

16. Tudor Car L, Marcano BJ, Nikolaou C, Majeed A, Zary N, Car J. Mobile learning for delivering health professional education. Cochrane Database Syst Rev 2015;9:CD011861. [doi: 10.1002/14651858.CD011861.pub2]

17. Dunleavy G, Nikolaou C, Nifakos S, Atun R, Law G, Tudor Car L. Mobile digital education for health professions: systematic review and meta-analysis by the Digital Health Education Collaboration. J Med Internet Res 2019 Feb 12;21(2):e12937 [FREE Full text] [doi: 10.2196/12937] [Medline: 30747711]

18. Saxena NK, Vseteckova J, Dev P, Paul P, Lim K, Kononowicz A, et al. Virtual reality environments for health professional education (Protocol). Cochrane Database Syst Rev 2016:CD012090 [FREE Full text] [doi: 10.1002/14651858.cd012090]

19. Vash JH, Yunesian M, Shariati M, Keshvari A, Harirchi I. Virtual patients in undergraduate surgery education: a randomized controlled study. ANZ J Surg 2007;77(1-2):54-59. [doi: 10.1111/j.1445-2197.2006.03978.x] [Medline: 17295822] 
20. Kyaw BM, Saxena N, Posadzki P, Vseteckova J, Nikolaou C, George P, et al. Virtual reality for health professions education: systematic review and meta-analysis by the Digital Health Education Collaboration. J Med Internet Res 2019 Jan 22;21(1):e12959 [FREE Full text] [doi: 10.2196/12959] [Medline: 30668519]

21. Stellflug SM. The Effect of Simulation Training on Knowledge Retention and Skill Self Efficacy in Pedatric Advanced Life Support Courses [thesis]. Boulder: University of Colorado; May 2015.

22. Vestergaard L, Loofgren B, Jessen C, Boorlum C, Wolff A, Nielsen H. Pediatric basic life support self-training is comparable to instructor-led training: a randomized manikin study. Circulation 2011;124(21):A156.

23. Sharara-Chami R, Taher S, Kaddoum R, Tamim H, Charafeddine L. Simulation training in endotracheal intubation in a pediatric residency. Middle East J Anaesthesiol 2014;22(5):477-485. [doi: 10.5005/jp/books/12116 19]

24. Cook DA, Levinson AJ, Garside S, Dupras DM, Erwin PJ, Montori VM. Instructional design variations in internet-based learning for health professions education: a systematic review and meta-analysis. Acad Med 2010 May;85(5):909-922. [doi: 10.1097/ACM.0b013e3181d6c319] [Medline: 20520049]

25. Lahti M, Hätönen H, Välimäki M. Impact of e-learning on nurses' and student nurses knowledge, skills, and satisfaction: a systematic review and meta-analysis. Int J Nurs Stud 2014 Jan;51(1):136-149. [doi: 10.1016/j.ijnurstu.2012.12.017] [Medline: 23384695]

26. World Health Organization. 2015. eLearning for undergraduate health professional education: a systematic review informing a radical transformation of health workforce development URL: http://whoeducationguidelines.org/sites/default/files/ uploads/eLearning?healthprof?report.pdf [accessed 2017-12-11] [WebCite Cache ID 77CjyoX0e]

27. Semwal M, Whiting P, Bajpai R, Bajpai S, Kyaw B, Tudor Car L. Digital education for health professions on smoking cessation management: systematic review by the Digital Health Education Collaboration. J Med Internet Res 2019 Mar 04;21(3):e13000 [FREE Full text] [doi: 10.2196/13000] [Medline: 30829576]

28. Glegg SMN, Livingstone R, Montgomery I. Facilitating interprofessional evidence-based practice in paediatric rehabilitation: development, implementation and evaluation of an online toolkit for health professionals. Disabil Rehabil 2016;38(4):391-399. [doi: 10.3109/09638288.2015.1041616] [Medline: 25924019]

29. Lewis KO, Cidon MJ, Seto TL, Chen H, Mahan JD. Leveraging e-learning in medical education. Curr Probl Pediatr Adolesc Health Care 2014 Jul;44(6):150-163. [doi: 10.1016/j.cppeds.2014.01.004] [Medline: 24981664]

30. Rao A, O'Leary F. Training clinicians to care for children in emergency departments. J Paediatr Child Health 2016 Feb;52(2):126-130. [doi: 10.1111/jpc.13108] [Medline: 27062614]

31. PROSPERO. 2017. eLearning interventions for continuous medical education of health care professionals on pediatrics URL: http://www.crd.york.ac.uk/PROSPERO/display record.php?ID=CRD42017057793 [accessed 2019-03-27] [WebCite Cache ID 77BNZXkpv]

32. Car J, Carlstedt-Duke J, Tudor Car L, Posadzki P, Whiting P, Zary N, Digital Health Education Collaboration. Digital education in health professions: the need for overarching evidence synthesis. J Med Internet Res 2019 Feb 14;21(2):e12913 [FREE Full text] [doi: 10.2196/12913] [Medline: 30762583]

33. Sangrà A, Vlachopoulos D, Cabrera N. Building an inclusive definition of e-learning: an approach to the conceptual framework. IRRODL 2012 Apr 13;13(2):145. [doi: 10.19173/irrodl.v13i2.1161]

34. Gentry SV, Gauthier A, L'Estrade Ehrstrom B, Wortley D, Lilienthal A, Tudor Car L, et al. Serious gaming and gamification education in health professions: systematic review. J Med Internet Res 2019 Mar 28;21(3):e12994 [FREE Full text] [doi: 10.2196/12994] [Medline: $\underline{30920375]}$

35. George PP, Zhabenko O, Kyaw BM, Antoniou P, Posadzki P, Saxena N, et al. Online digital education for postregistration training of medical doctors: systematic review by the Digital Health Education Collaboration. J Med Internet Res 2019 Feb 25;21(2):e13269 [FREE Full text] [doi: 10.2196/13269] [Medline: 30801252]

36. Posadzki P, Bala M, Kyaw BM, Semwal M, Divakar U, Koperny M, et al. Offline digital education for postregistration health professions: systematic review and meta-analysis by the Digital Health Education Collaboration. J Med Internet Res 2019 Apr 24;21(4):e12968 [FREE Full text] [doi: 10.2196/12968] [Medline: $\underline{\text { 31017584] }}$

37. International Standard Classification of Occupations. 2008. Options for the classification of health occupations in the Updated International Standard Classification of Occupations (ISCO-08) URL: http://www.ilo.org/public/english/bureau/ stat/isco/docs/healthocc.pdf [accessed 2019-08-21] [WebCite Cache ID 77BOwmvDC]

38. Wan X, Wang W, Liu J, Tong T. Estimating the sample mean and standard deviation from the sample size, median, range and/or interquartile range. BMC Med Res Methodol 2014 Dec 19;14:135 [FREE Full text] [doi: 10.1186/1471-2288-14-135] [Medline: 25524443]

39. Cook DA, Hatala R, Brydges R, Zendejas B, Szostek JH, Wang AT, et al. Technology-enhanced simulation for health professions education: a systematic review and meta-analysis. JAMA 2011 Sep 07;306(9):978-988. [doi: 10.1001/jama.2011.1234] [Medline: 21900138]

40. Higgins JG. The Cochrane Collaboration. 2011. Cochrane Handbook for Systematic Reviews of Interventions Version 5.1 URL: http://handbook-5-1.cochrane.org/ [accessed 2019-08-21]

41. Puffer S, Torgerson D, Watson J. Evidence for risk of bias in cluster randomised trials: review of recent trials published in three general medical journals. BMJ 2003 Oct 04;327(7418):785-789 [FREE Full text] [doi: 10.1136/bmj.327.7418.785] [Medline: 14525877$]$ 
42. Ryan R. Cochrane Consumers and Communications Review Group. 2016 Dec. Heterogeneity and subgroup analyses in Cochrane Consumers and Communication Group reviews: planning the analysis at protocol stage URL: https://cccrg. cochrane.org/sites/cccrg.cochrane.org/files/public/uploads/heterogeneity subgroup analyses revising december 1 st 2016. pdf [accessed 2019-08-21] [WebCite Cache ID 77BRawcWD]

43. Schünemann H, Oxman A, Higgins J, Vist G, Glasziou P, Guyatt G. Presenting results and "summary of findings" tables. Cochrane Handbook for Systematic Reviews of Interventions 2008:335-357. [doi: 10.1002/9780470712184.ch11]

44. Jain A, Agarwal R, Chawla D, Paul V, Deorari A. Tele-education vs classroom training of neonatal resuscitation: a randomized trial. J Perinatol 2010 Dec;30(12):773-779. [doi: 10.1038/jp.2010.42] [Medline: 20357810]

45. Lund S, Boas IM, Bedesa T, Fekede W, Nielsen HS, Sørensen BL. Association between the safe delivery app and quality of care and perinatal survival in ethiopia: a randomized clinical trial. JAMA Pediatr 2016 Aug 01;170(8):765-771. [doi: 10.1001/jamapediatrics.2016.0687] [Medline: 27322089]

46. Koele-Schmidt L, Vasquez MM. NewB for newbies: a randomized control trial training housestaff to perform neonatal intubation with direct and videolaryngoscopy. Paediatr Anaesth 2016 Apr;26(4):392-398. [doi: 10.1111/pan.12832] [Medline: 26714736]

47. Campbell DM, Barozzino T, Farrugia M, Sgro M. High-fidelity simulation in neonatal resuscitation. Paediatr Child Health 2009 Jan;14(1):19-23 [FREE Full text] [doi: 10.1093/pch/14.1.19] [Medline: 19436459]

48. Donoghue A, Durbin D, Nadel F, Stryjewski GR, Kost SI, Nadkarni VM. Effect of high-fidelity simulation on Pediatric Advanced Life Support training in pediatric house staff: a randomized trial. Pediatr Emerg Care 2009 Mar;25(3):139-144. [doi: 10.1097/PEC.0b013e31819a7f90] [Medline: 19262421]

49. Benjamin SE, Tate DF, Bangdiwala SI, Neelon BH, Ammerman AS, Dodds JM, et al. Preparing child care health consultants to address childhood overweight: a randomized controlled trial comparing web to in-person training. Matern Child Health J 2008 Sep;12(5):662-669. [doi: 10.1007/s10995-007-0277-1] [Medline: 17713847]

50. Pollak KI, Tulsky JA, Bravender T, Østbye T, Lyna P, Dolor RJ, et al. Teaching primary care physicians the 5 A's for discussing weight with overweight and obese adolescents. Patient Educ Couns 2016 Oct;99(10):1620-1625 [FREE Full text] [doi: 10.1016/j.pec.2016.05.007] [Medline: 27228899]

51. Alade K, Caviness A, Miller S, Press G. Evaluation of a pediatric emergency ultrasonography course. Ann Emerg Med 2012 Oct;60(4):S68. [doi: 10.1016/j.annemergmed.2012.06.167]

52. Dingeldein L, Sheehan K, Krcmarik M, Dowd MD. Evaluation of a firearm injury prevention web-based curriculum. Teach Learn Med 2012;24(4):327-333. [doi: 10.1080/10401334.2012.715254] [Medline: 23036000]

53. Smeekens AEFN, Broekhuijsen-van Henten DM, Sittig JS, Russel IMB, ten Cate OTJ, Turner NM, et al. Successful e-learning programme on the detection of child abuse in emergency departments: a randomised controlled trial. Arch Dis Child 2011 Apr;96(4):330-334. [doi: 10.1136/adc.2010.190801] [Medline: 21233084]

54. Gordon M, Chandratilake M, Baker P. Improved junior paediatric prescribing skills after a short e-learning intervention: a randomised controlled trial. Arch Dis Child 2011 Dec;96(12):1191-1194. [doi: 10.1136/archdischild-2011-300577] [Medline: 22080459]

55. Zaveri PP, Davis AB, O'Connell KJ, Willner E, Aronson Schinasi DA, Ottolini M. Virtual reality for pediatric sedation: a randomized controlled trial using simulation. Cureus 2016 Feb 09;8(2):e486 [FREE Full text] [doi: 10.7759/cureus.486] [Medline: 27014520]

56. Kim S, Shin G. Effects of nursing process-based simulation for maternal child emergency nursing care on knowledge, attitude, and skills in clinical nurses. Nurse Educ Today 2016 Feb;37:59-65. [doi: 10.1016/j.nedt.2015.11.016] [Medline: 26655857]

57. Gordon JS, Mahabee-Gittens EM, Andrews JA, Christiansen SM, Byron DJ. A randomized clinical trial of a web-based tobacco cessation education program. Pediatrics 2013 Feb;131(2):e455-e462 [FREE Full text] [doi: 10.1542/peds.2012-0611] [Medline: 23319529]

58. Hearty T, Maizels M, Pring M, Mazur J, Liu R, Sarwark J, et al. Orthopaedic resident preparedness for closed reduction and pinning of pediatric supracondylar fractures is improved by e-learning: a multisite randomized controlled study. J Bone Joint Surg Am 2013 Sep 04;95(17):e1261-e1267. [doi: 10.2106/JBJS.L.01065] [Medline: 24005210]

59. Le TT, Rait MA, Jarlsberg LG, Eid NS, Cabana MD. A randomized controlled trial to evaluate the effectiveness of a distance asthma learning program for pediatricians. J Asthma 2010 Apr;47(3):245-250. [doi: 10.3109/02770900903560209] [Medline: 20394510]

60. Thomas EJ, Williams AL, Reichman EF, Lasky RE, Crandell S, Taggart WR. Team training in the neonatal resuscitation program for interns: teamwork and quality of resuscitations. Pediatrics 2010 Mar;125(3):539-546. [doi:

10.1542/peds.2009-1635] [Medline: 20156896]

61. CONSORT. CONSORT 2010 explanation and elaboration: updated guidelines for reporting parallel group randomised trials. BMJ 2011 Sep 29;343(sep29 2):d6131-d6131. [doi: 10.1136/bmj.d6131]

62. Pakenham-Walsh N, Bukachi F. Information needs of health care workers in developing countries: a literature review with a focus on Africa. Hum Resour Health 2009 Apr 08;7:30 [FREE Full text] [doi: 10.1186/1478-4491-7-30] [Medline: 19356239] 
63. Ameh CA, Kerr R, Madaj B, Mdegela M, Kana T, Jones S, et al. Knowledge and skills of healthcare providers in sub-Saharan Africa and Asia before and after competency-based training in emergency obstetric and early newborn care. PLoS One 2016;11(12):e0167270 [FREE Full text] [doi: 10.1371/journal.pone.0167270] [Medline: 28005984]

\author{
Abbreviations \\ CME: continuing medical education \\ CONSORT: Consolidated Standards of Reporting Trials \\ CRCT: cluster randomized controlled trial \\ GRADE: Grading of Recommendations, Assessment, Development, and Evaluations \\ HIC: high-income countries \\ LMIC: low- and middle-income countries \\ OR: odds ratio \\ RCT: randomized controlled trial \\ SMD: standardized mean difference
}

\author{
Edited by G Eysenbach; submitted 16.04.19; peer-reviewed by IN Gomez, J Derzon; comments to author 15.06.19; revised version \\ received 17.07.19; accepted 18.08.19; published 25.09.19 \\ Please cite as: \\ Brusamento S, Kyaw BM, Whiting P, Li L, Tudor Car L \\ Digital Health Professions Education in the Field of Pediatrics: Systematic Review and Meta-Analysis by the Digital Health Education \\ Collaboration \\ J Med Internet Res 2019;21(9):e14231 \\ URL: https://www.jmir.org/2019/9/e14231 \\ doi: $10.2196 / 14231$ \\ PMID: $\underline{31573906}$
}

CSerena Brusamento, Bhone Myint Kyaw, Penny Whiting, Li Li, Lorainne Tudor Car. Originally published in the Journal of Medical Internet Research (http://www.jmir.org), 25.09.2019 This is an open-access article distributed under the terms of the Creative Commons Attribution License (https://creativecommons.org/licenses/by/4.0/), which permits unrestricted use, distribution, and reproduction in any medium, provided the original work, first published in the Journal of Medical Internet Research, is properly cited. The complete bibliographic information, a link to the original publication on http://www.jmir.org/, as well as this copyright and license information must be included. 